\title{
IMPACTOS PSICOSSOCIAIS ASSOCIADOS ÀS MANCHAS GRAVÍDICAS
}

\author{
Maristela Belletti Mutt Urasaki ${ }^{1}$, Maria Helena Sant Ana Mandelbaum², RoselaneGonçalves ${ }^{3}$
}

\begin{abstract}
RESUMO: A pele é um órgão de grande visibilidade e reconhecimento exterior; suas alterações podem provocar significativo impacto psicológico. Considerando as alterações que ocorrem na gravidez e a importância do planejamento de ações estratégicas e preventivas, este estudo objetivou descrever e analisar as repercussões de manchas gravídicas no cotidiano de mulheres acometidas. Participaram 84 puérperas atendidas em unidades básicas de saúde. Os dados foram coletados por meio de entrevista e o tratamento baseou-se na análise temática. As respostas codificadas resultaram em cinco categorias: sentimentos de insatisfações; autoimagem e dimensão estética prejudicadas; estratégias para dissimular a mancha; dificuldades enfrentadas e percepção sobre o conceito de normalidade. As falas das participantes evidenciaram sofrimento psíquico; verificou-se que as manchas de pele se integram ao viver das mulheres, assumem importante sentido uma vez que repercutem nas esferas emocional, relacional e financeira. Este quadro exige revisão das práticas atualmente empregadas no atendimento das mulheres.
\end{abstract}

DESCRITORES: Pele; Melanose; Gravidez; Enfermagem.

\section{PSYCHO-SOCIAL IMPACTS ASSOCIATED WITH MELASMA (MASK OF PREGNANCY)}

ABSTRACT: The skin is an organ with great visibility and exterior recognition: its changes can provoke a significant psychological impact. Considering the changes which occur during pregnancy and the importance of the planning of strategic and preventive actions, this study aimed to describe and analyze the repercussions of the mask of pregnancy in the routine of women affected by it. 84 puerperas attended in primary health centers participated. The data was collected by interview and the treatment was based in thematic analysis. The codified responses resulted in five categories: feelings of dissatisfaction; impaired self-image and esthetic dimensions; strategies for hiding the mark; difficulties faced and perception on the concept of normality. The participants' accounts evidenced psychological suffering; it was ascertained that the skin blemishes are integrated into the women's lives, and take on an important meaning because they impact on the emotional, relational and financial spheres. This situation requires the practices currently used in attending these women to be reviewed.

DESCRIPTORS: Skin; Melanosis; Pregnancy; Nursing.

\section{IMPACTOS PSICOSOCIALES ASOCIADOS A LAS MANCHAS DEL EMBARAZO}

RESUMEN: La piel es un órgano de gran visibilidad y reconocimiento exterior; sus alteraciones pueden provocar significativo impacto psicológico. Considerando las alteraciones que ocurren en el embarazo y la importancia del planeamiento de acciones estratégicas y preventivas, este estudio tuvo el objetivo de describir y analizar las repercusiones de manchas gravídicas en el cotidiano de mujeres afligidas. Participaron 84 puérperas atendidas en unidades básicas de salud. Los datos fueron obtenidos por medio de entrevista y el tratamiento fue basado en el análisis temático. Las respuestas codificadas resultaron en cinco categorías: sentimientos de insatisfacción; autoimagen y dimensión estética perjudicadas; estrategias para disimular la mancha; dificultades afrontadas y percepción acerca del concepto de normalidad. Las hablas de las participantes evidenciaron sufrimiento psíquico; se verificó que las manchas de la piel se integran al vivir de las mujeres, asumen importante papel una vez que repercuten en las esferas emocional, relacional y financiera. Este cuadro exige revisión de las prácticas actualmente empleadas en el atendimiento de las mujeres. DESCRIPTORES: Piel; Melanosis; Gravidez; Enfermería.

${ }^{1}$ Enfermeira. Doutora em Enfermagem. Professora do Curso de Graduação em Obstetrícia da Escola de Artes, Ciências e Humanidades da Universidade de São Paulo.

${ }^{2}$ Enfermeira. Doutora em Educação. Supervisora Regional Tecsaúde da Secretaria de Saúde do Município de São Paulo. Coordenadora de Enfermagem do Projeto Dermacamp do Centro de Estudos Dermatológicos da Universidade de Taubaté. Membro do Grupo de Pesquisa em Cuidados com a Pele: Cuidarte.

${ }^{3}$ Enfermeira. Doutora em Enfermagem. Professora do Curso de Graduação em Obstetrícia da Escola de Artes, Ciências e Humanidades da Universidade de São Paulo. Membro do Grupo de Pesquisa em Enfermagem com Abordagens Fenomenológicas.

Autor correspondente:

Recebido: 16/10/2012

Maristela Belletti Mutt Urasaki

Aprovado: 18/09/2013

Universidade de São Paulo

Av. Arlindo Bettio, 1000 - 03828-000 - São Paulo-SP-Brasil

E-mail: mari.urasaki@usp.br 


\section{INTRODUÇÃO}

A pele é um órgão de grande visibilidade e reconhecimento exterior; consiste interface entre o eu e o outro, o eu e o mundo, o interno e o externo, auta de forma dual, pois ao mesmo tempo em que consiste em uma espécie de sistema de abrigo da individualidade, expõe ao contato com o ambiente e o outro; tem uma função ego lógica, isto é, compõe a autoimagem e a autoconfiança. Alterações em sua aparência e funcionamento podem provocar significativo impacto psicológico, como demonstram as evidências, tanto oriundas da experiência clínica, como fundamentadas em alguns estudos da literatura ${ }^{(1)}$. Outras investigações também apontam a estreita ligação com a qualidade de $\operatorname{vida}^{(2-3)}$.

De maneira geral, as dermatoses afetam a autoimagem e têm grande potencial para desencadear processos que afetam a autoestima, gerando sentimentos que podem se manifestar por ansiedade, tristeza ou até mesmo quadros depressivos ${ }^{(4)}$. As manchas gravídicas, que surgem na gestação, e com possibilidade de permanecer por longo tempo no período puerperal ou definitivamente, podem ser percebidas de forma negativa pela mulher, causando significativo impacto no seu bem-estar. Aliada a esta situação soma-se o fato das máculas se localizarem, primariamente, na face.

Necessário lembrar que, superados os novos desafios e demandas iniciais próprias da maternidade, a mulher tende a retomar o olhar sobre si e neste momento, a percepção das mudanças em sua imagem corporal pode ser de insatisfação, especialmente com a pele, em função de sua visibilidade.

A adoção de medidas preventivas e a preparação física e psicológica para as mudanças advindas da maternidade são fatores de proteção psicossocial $^{(5)} \mathrm{e}$ devem fazer parte das estratégias de cuidado implementadas pela equipe de saúde, na qual a enfermagem desempenha importante papel, especialmente nas ações de educação, promoção e prevenção de agravos à saúde ${ }^{(6)}$.

Neste sentido, o objetivo desse estudo foi descrever e analisar as repercussões das manchas gravídicas no cotidiano das mulheres acometidas, para que os profissionais conheçam os impactos do problema e elaborem ações estratégicas para sua prevenção no ciclo gravídico-puerperal.

\section{MÉTODO}

Trata-se de um estudo descritivo exploratório com desenho transversal, realizado a partir dos dados de uma pesquisa base cujo objeto de estudo foi manchas de pele na gravidez.

As participantes da investigação foram mulheres maiores de 18 anos que estavam no período puerperal dentro do intervalo de três a vinte e quatro meses pós-parto. Este tempo foi estabelecido tendo em vista que a melhora espontânea do quadro ocorre nos primeiros meses pós-parto. Outro critério de inclusão adotado foi não apresentar outros problemas dermatológicos na ocasião do período gravídico puerperal.

Os dados foram coletados em quatro unidades básicas de saúde da zona leste do Município de São Paulo, no primeiro semestre de 2010, por ocasião do retorno da mulher e bebê à puericultura.

$\mathrm{Na}$ pesquisa base foi aplicado um formulário a 234 puérperas, selecionadas por conveniência, cujos resultados mostraram uma frequência de 104 (44,4\%) mulheres afirmando presença de manchas de pele durante a gestação. Estas responderam uma questão sobre o grau de desconforto sentido em relação ao quadro. Empregou-se uma escala de cinco níveis variando desde "não incomodam" até "incomodam muitíssimo"; 84 mulheres referiram algum desconforto, sendo que a maioria referiu alto grau. Estas participantes foram posteriormente convidadas a responderem a uma questão aberta: "fale-me sobre este incômodo". Este artigo apresenta e discute os resultados obtidos a partir desta questão.

A pesquisa de base obedeceu a Resolução de n. 196/96 do Conselho Nacional de Saúde. Foi assegurado, às participantes, sigilo e anonimato quanto às informações prestadas. Todas foram identificadas com a letra "P", seguida do número da entrevista. A pesquisa foi aprovada pelo Comitê de Ética em Pesquisa da Secretaria Municipal de Saúde de São Paulo (CEP/ SMS 413/09).

O tratamento dos dados baseou-se na análise temática $^{(7)}$. Foram realizadas as primeiras leituras de contato inicial com o texto global, denominada leitura flutuante; posteriormente o texto foi desmembrado em unidades, em diferentes núcleos de sentido e, nessa etapa, um código de cores foi utilizado para identificar os temas. A etapa seguinte foi o agrupamento das unidades em categorias. Durante o processo de leitura e análise das respostas percebeu-se que algumas falas expressavam idéias que poderiam pertencer a mais de uma categoria ou mais de um tema, desta forma foi buscado consenso entre as autoras para melhor situá-las. 


\section{RESULTADOS}

As 84 puérperas participantes tinham entre $18 \mathrm{e}$ 48 anos, todas frequentaram a escola, sendo o ensino médio completo a modalidade de ensino mais citada. A renda familiar declarada pela maioria situou-se entre um e dois salários mínimos mensais.

A análise das falas codificadas resultou em cinco categorias, quais sejam: sentimentos de insatisfações; autoimagem e dimensão estética prejudicadas; estratégias para dissimular a mancha; dificuldades enfrentadas e percepção sobre o conceito de normalidade.

\section{Sentimentos de insatisfações}

As mulheres que tiveram manchas de pele na gestação expressaram sofrimento relacionado ao quadro. Sessenta falas envolveram sentimentos de vergonha, medo, tristeza, raiva e frustração; algumas delas descreveram mais de um sentimento.

O sentimento de vergonha da aparência foi verbalizado de forma contundente pelas participantes, e mencionado não apenas nas relações profissionais e sociais mais amplas, como também nas relações familiares:

Fiquei feia e com vergonha das pessoas, quase não saia para passear, só mesmo prá ir trabalhar porque era obrigada [...]. (P2)

Tive vergonha do meu marido e das minhas primas, que nunca tiveram [...]. (P12)

Ficou feio, esquisito, fiquei com vergonha de usar algumas roupas, tive manchas no pescoço [...]. (P28)

Me incomodou por causa do trabalho, com vergonha das pessoas e porque sou muito vaidosa [...]. (P72)

O medo foi expresso por várias participantes e relacionado ao risco de permanência definitiva da mancha, do quadro significar doença grave, e de outras perdas:

Fiquei com medo de ser doença procurei o médico, pois toda minha família teve doença ruim, mas foi apenas coincidência [...]. (P14)

Fiquei preocupada e com medo de não sumir após a gestação [...]. (P7)

Tive medo do meu marido me deixar [...]. (P11)
Fiquei com muita vergonha das pessoas e tive medo de ser doença, não conhecia os motivos dessas manchas. (P44)

O sentimento de tristeza também foi mencionado e atribuído à insatisfação com a alteração da aparência percebida:

Fiquei triste porque da primeira gravidez não tive nada, e do Isaac, além do rosto manchado, ainda vieram as estrias, então fiquei horrivel. Agora eu não sei se ainda é pouco tempo para o tratamento fazer efeito, mas ainda não tive o resultado que esperava [...]. (P41)

Fiquei horrivel e muito triste. Achei que não fosse sumir e que meu esposo me rejeitasse. (P26)

Achei que não fosse sumir nunca mais e fiquei com depressão, então uma amiga me indicou uma esteticista que ela conhecia e comecei a tratar; ainda não sumiu tudo, mas vou continuar; deixo de comprar o que for prá pagar a sessão, mas não paro [...]. (P39)

Algumas mulheres também expressaram sentimento de raiva por terem que conviver com algo não esperado e não desejado:

Fiquei com raiva porque das outras gravidez não tive nada e dessa última, além de passar muito mal, apareceram manchas no rosto todo [...]. (P31)

Odiei. Ainda bem que tive pouca [mancha]. (P42)

Não me sentia bem, ficava com raiva ao me olhar no espelho [...]. (P63)

Tive muitas manchas, fiquei horrivel, morria de vergonha e raiva ao me olhar no espelho. Ainda bem que sumiu tudo [...]. (P4)

Além dos sentimentos de vergonha, medo, tristeza e raiva, o comprometimento da autoimagem implicou em sofrimento para as mulheres.

\section{Autoimagem e dimensão estética prejudicadas}

Quarenta e seis mulheres destacaram a mudança estética provocada pela mancha; algumas ressaltaram a questão da visibilidade, da intensidade e da localização da pigmentação como um problema a ser enfrentado: 
Ouvia piadinha das pessoas dizendo que eu era de duas cor [...]. (P39)

Tenho a pele muito clara e incomodava porque ficou bem visivel [...]. (P10)

As manchas eram escuras e próximas dos olhos, ficava incomodada quando alguém perguntava [...]. (P15)

É feio, me sentia mal, se tivesse ficado para sempre, nem sei! (P22)

Não acho bonito, se fosse limpinho seria melhor; quem não quer ter uma pele sem mancha. São marcas de sol, dá aspecto de sujo [...]. ( $\mathrm{P} 1)$

Me incomoda mais agora que não estou grávida porque na gravidez é normal; o corpo muda, aparece manchas, mas esperava que sumisse tudo e rápido. (P47)

Afetou a estética, a autoestima; afeta a higiene, dá impressão de estar encardida. (P28)

Sempre fui vaidosa, a gente fica com cara de cansada. (P63)

A percepção da autoimagem comprometida levou a busca de estratégias para disfarçar o que estava visível.

\section{Estratégias para dissimular a mancha}

Dezesseis puérperas enfatizaram a necessidade de esconder a mancha; citaram diferentes estratégias como uso de maquiagem, roupas discretas e isolamento social:

Trabalho com o público, preciso me maquiar muito. O trabalho exige que eu fique maquiada, tenha boa aparência. Não só pelo trabalho, de qualquer maneira fica feio. (P72)

Evitava roupas que apareciam as manchas [...]. (P2)

Fiquei com vergonha de sair de casa; ficava com a mão no queixo o tempo todo para esconder [...]. (P58)

Fiquei muito feia e com vergonha dos meus amigos, agora só saio de casa com maquiagem, da base até o rímel para esconder [...]. (P15)

Ficou horrivel, feio. Evitava sair com as minhas ami- gas. Festa nem pensar! (P57)

Além das estratégias adotadas para disfarçar as manchas, a condição de ser portadora de mancha gravídica levou a outros enfrentamentos e dificuldades, na medida em que buscaram ajuda profissional e outros recursos estéticos.

\section{Dificuldades enfrentadas}

Dentre as dificuldades enfrentadas foram mencionados: falta de dinheiro para iniciar o tratamento e para manter as despesas para o cumprimento dos cuidados propostos e desapontamento com resultados insatisfatórios. Estes aspectos foram citados por onze participantes, a seguir alguns exemplos:

Fiquei com muita vergonha no começo, até procurei um dermatologista pelo SUS, mas os cremes tinham que mandar fazer e são muito caros, ai fiquei assim mesmo. (P70)

Tive muita vergonha da minha aparência, pois fiquei horrivel, tive mancha já na primeira gestação e mesmo com o tratamento na segunda gestação elas pioraram, e só melhoraram com a continuação do tratamento após a gestação [...]. (P33)

Não tenho como fazer nenhum tratamento porque os produtos são caros, então passo base e blush que compro em qualquer lugar, mais barato para poder sair na rua [...]. (P31)

Logo que as manchas começaram aparecer minha prima, que vende cosméticos, me falou de um creme clareador, então comprei e comecei a passar e realmente melhorou, mas não sumiu; achei que quando o bebênascesse sumiria tudo, mas até agora não aconteceu. É tempo e dinheiro. (P1)

Não posso comprar protetor nem creme. (P7)

A tentativa de resolução do problema mostrou-se como um enfrentamento solitário, uma vez que para muitos, incluindo os profissionais de saúde, as manchas gravídicas são consideradas como alterações normais.

\section{Percepção sobre conceito de normalidade}

A subjetividade do conceito de normalidade aparece de forma subliminar nas falas de algumas mulheres: 
Fiquei muito incomodada por causa da aparência e do trabalho; e não achei nada normal como o médico falou. (P69)

Não achei nada normal como falavam [...]. (P12)

Fiquei horrivel e com muita raiva, e além disso, tive muitas espinhas e meu médico só falava que era normal! (P54)

\section{DISCUSSÃO}

Os discursos das participantes evidenciaram sofrimento psíquico que suscitam reflexões sobre o quanto um problema orgânico, considerado comum, pode dificultar a experiência do processo de gestação e puerpério. Os resultados também demonstraram a importância da imagem corporal para essas mulheres, e sua relação com a autoestima.

A imagem corporal diz respeito à percepção da imagem que uma pessoa tem do seu próprio corpo e dos sentimentos gerados por esta percepção; é vista por estudiosos como uma entidade em constante autoconstrução e autodestruição, em constante mudança, crescimento e desenvolvimento. Estão envolvidos processos conscientes e inconscientes fazendo parte as experiências, memórias, intenções e aspirações. Abarca ainda a relação com o meio e com as imagens corporais dos outros, assim como as atitudes dos outros com seus próprios corpos e suas relações. É uma representação mental que se faz de si mesmo; sendo plástica e mutável imprime significados diferentes e individualizados $^{(8)}$. É fortemente condicionada por padrões sociais interferindo no comportamento, particularmente nas relações interpessoais ${ }^{(9)}$.

A insatisfação vivida pelas puérperas participantes, manifestada por sentimentos de vergonha, tristeza e raiva, pode ser também compreendida quando se considera que o primeiro contato do ser humano com o mundo externo se dá por meio da pele. Ela é o campo no qual a simbólica da interação eu-outro acontece maciçamente visto ser ela o envoltório, o que põe em contato com o mundo, com o meio e com o outro ${ }^{(10)}$.

Neste sentido, na medida em que uma pessoa percebe mudanças físicas em sua aparência, essa condição pode causar sofrimento e alterações em sua vida, implicando em prejuízos na rotina diária, socialização e perdas de uma forma geral. Dados sociológicos e psicológicos, cada vez mais, indicam que os problemas de pele podem ter sérias consequências ao gerar vergonha, ansiedade e constrangimento social ${ }^{(11-14)}$.

Importa observar que a pressão social para o alcance de um padrão ideal de beleza pode suscitar frustração, descontentamento e rejeição quanto à própria aparência $^{(13)}$. As pessoas podem vivenciar sentimentos de inadequação e estigma frente às exigências atuais de estética, sendo que o sentimento de discriminação pode gerar insatisfação consigo e a adaptação ao problema ser um foco causador de estresse ${ }^{(15)}$.

As implicações das manchas de pele na qualidade de vida têm sido estudadas por alguns autores. Os resultados descritos são similares aos encontrados nesta investigação; as esferas da vida mais afetadas estão no campo emocional e social ${ }^{(3,16-18)}$. Um desses estudos, além de avaliar o prejuízo e o grau de limitação que o melasma acarretou na qualidade de vida de mulheres, investigou se havia correlação com o grau de gravidade do quadro. $O$ estudo não mostrou correlação; este resultado fortalece a idéia que a gravidade da mancha não é o único critério determinante para a percepção da limitação. Os autores afirmam que o médico corre o risco de diagnosticar uma forma leve da doença enquanto a percepção da cliente aponta na direção oposta, causando-lhe sofrimento ${ }^{(3)}$. Entende-se que todos os profissionais de saúde, inclusive a equipe de enfermagem, correm o risco de subestimar o problema.

Outra investigação realizada com mulheres enfatizou os prejuízos na esfera relacional, no convívio social e nas atividades de lazer ${ }^{(2)}$. O mesmo grupo repetiu o estudo com uma amostra maior e encontraram novamente preocupação com a aparência da pele, sensação de ser olhado pelos outros (no sentido de não ser atraente), limitação das atividades sociais e de lazer, além do uso de cosméticos com o objetivo de esconder a hiperpigmentação ${ }^{(19)}$.

A intensidade da interferência do quadro na qualidade de vida, segundo alguns autores, é proporcional ao tempo que a pessoa acometida convive com o proble$\mathrm{ma}^{(16)}$. Em relação às manifetações das entrevistadas sobre o sentimento de medo, especialmente as afirmações associadas a doença grave e perigosa, levam a acreditar que as mulheres conviveram com um problema para $o$ qual não haviam sido preparadas. É sabido que as respostas das pessoas aos problemas de saúde variam muito e tem relação com suas crenças, valores e expectativas. A maneira como cada uma enfrenta as alterações cutâneas reflete em respostas emocionais diversas ${ }^{(13)}$. Desta forma, compete aos profissionais ajudá-las.

A relação entre os profissionais e pessoas com problemas com potencial para sofrimento psíquico deve 
ser pautada na confiança. Na área da Dermatologia é essencial, pois a resposta e a adesão ao tratamento e, até mesmo a resiliência diante de eventuais falhas no tratamento, dependem da boa relação profissional ${ }^{(12)}$. Estudiosos da Enfermagem têm se dedicado a esta questão considerando que muitas queixas e problemas podem ser resolvidos, ou atenuados, quando as pessoas se sentem ouvidas, compreendidas e respeitadas pelos profissionais. Os autores enfatizam a importância da escuta e apontam que não é uma tarefa fácil, pois é necessário ter disponibilidade para essa ação, que por sua vez, faz refletir sobre a forma de pensar e de suspender idéias pré-definidas ${ }^{(20)}$.

Outro importante aspecto observado em diversas falas das participantes diz respeito à preocupação com a visibilidade da mácula. A localização de uma lesão em áreas descobertas da pele pode trazer maior ou menor grau de constrangimento à pessoa acometida, tendo em vista $\mathrm{a}$ exposição do problema ao olhar do outro ${ }^{(1)}$. Vergonha, ansiedade e tristeza são mencionadas pelas mulheres com a pele comprometida, principalmente em áreas descobertas.

Diferenças significativas na qualidade de vida foram observadas em um grupo de portadores de lesões específicas no rosto e/ou mãos em comparação ao grupo com lesões generalizadas pelo corpo ${ }^{(21)}$. No âmbito das relações sociais, o que o corpo mostra em sua superfície pode causar constrangimentos e sentimentos de prejuízo na autoimagem, tornando o dia a dia de quem a experiência emocionalmente desgastante e, por consequência, dificultando o relacionamento interpessoal. A sensação de falta de autoconfiança é outro resultado desastroso que interfere no rendimento da pessoa no trabalho e nas relações sociais ${ }^{(12)}$.

Desta forma, parece salutar o mecanismo de adaptação adotado por algumas mulheres quando afirmam terem criado alternativas para camuflar aquilo que causou desconforto na autoimagem. A maquiagem foi uma das opções para melhorar a qualidade de vida, referida pelos participantes.

Estudo realizado sobre doenças de pele que apresentam fases de agudização e cronificação aponta que as formas de enfrentamento das doenças estão relacionadas aos esforços cognitivos, ou condutas, para manejar diretamente o fator estressante e estabelecer ações para não confrontar com o problema por meio de atitudes de fuga ${ }^{(15)}$. A atitude de fuga, neste estudo, foi percebida nas falas daquelas mulheres que disseram preferir isolar-se socialmente a enfrentar o olhar do outro.

As entrevistadas também apontaram, dentre os problemas vivenciados, dificuldades financeiras. Este dado é encontrado em outras investigações ${ }^{(12,16)}$. A renda familiar baixa, predominante no grupo, pode ter influenciado o acesso a terapêutica considerando o custo elevado dos produtos e do tratamento em geral. Este fato compromete o bem estar, pois o tratamento é benéfico para os aspectos clínicos que consequentemente repercutem nas esferas psicossociais ${ }^{(19)}$.

Para finalizar, algumas participantes falaram sobre suas insatisfações relacionadas ao fato do problema ser tratado como normal, e destacaram a forma como alguns profissionais de saúde concebem a condição. Entende-se que alguns pressupostos podem ajudar a equipe de saúde a manter essa visão: o fato do quadro não representar risco físico para a mãe e bebê, a baixa morbidade, a alta incidência na gestação, além do entendimento de que a gravidez é um processo natural e a mancha gravídica é uma condição fisiológica desse processo. Entretanto, é preciso reconhecer que este modelo de pensamento é o da simplificação e está ancorado em uma visão fragmentada e reducionista do ser humano. Os problemas vividos pelas mulheres podem passar totalmente despercebidos pelos profissionais, tendo em vista que cada pessoa tem uma representação singular de seu problema.

Quando se considera o impacto das manchas sobre a pele das mulheres, imediatamente é valorizado o campo dinâmico dessa questão, e não apenas seu aspecto estático, como se fosse um carimbo sobre uma folha. Passa-se a pensar no seu profundo significado quanto ao conjunto dos comportamentos e atitudes das mulheres, no seu movimento interior e exterior frente às manchas. Alguns pesquisadores ressaltam que qualquer subdivisão feita do assunto será, necessariamente, artificial, válida apenas para estudo teórico, pois, na prática, mesmo o mais simples movimento de uma pessoa envolverá toda uma dimensão emocional e circunstância que não tem como ser desconsiderada ${ }^{(8)}$.

Assim, destaca-se a necessidade emergente da equipe de saúde ampliar seu campo de visão e dar sentido às questões do outro como uma pessoa única, com suas próprias necessidades e expectativas. Esse modo de se relacionar requer disposição interna, interesse e respeito pelo outro. Neste contexto a Enfermagem pode ter importante contribuição, pois sua atuação nos programas de atenção integral à saúde da mulher deve incluir ações de promoção, prevenção e educação em saúde, além do encaminhamento adequado dos problemas que possam vir a ocorrer nesse período, dentre eles as manchas de pele ${ }^{(6)}$. 


\section{CONSIDERAÇÕES FINAIS}

Os resultados deste estudo sinalizaram que as manchas de pele em puérperas não se constituem como uma condição fisiológica apenas, mas se integraram ao viver das mulheres e assumem importante significado por provocar impactos consideráveis nas esferas emocional, relacional e financeira.

As falas das participantes remetem à necessidade de revisão das práticas atualmente empregadas pelos profissionais de saúde envolvidos no atendimento das mulheres no ciclo gravídico puerperal.

Recomenda-se que os problemas dermatológicos, considerados de baixa morbidade, sejam valorizados pela equipe de saúde, a qual deve adotar ações mais amplas que auxiliem as mulheres nas suas decisões e enfrentamentos. Ressalta-se a necessidade de capacitação das equipes com vistas ao cuidado baseado nos pressupostos da integralidade em saúde.

\section{REFERÊNCIAS}

1. Ludwig MWB, Muller MC, Redivo LB, Calvetti PU, Silva LM, Hauber LS, et al. Psicodermatologia e as intervenções do psicólogo da saúde. Mudanças - Psicologia da Saúde. [Internet] 2008;16(1) [acesso em 30 ago 2013]. Disponível: https://www.metodista. $\mathrm{br} / \mathrm{revistas} / \mathrm{revistas}-\mathrm{ims} / \mathrm{index} . \mathrm{php} / \mathrm{MUD} / \mathrm{article} /$ view/911/970

2. Balkrishnan R, Mcmichael AJ, Camacho FT, Saltzberg F, Housman TS, Grummer S, et al. Development and validation of a health-related quality of life instrument for women with melasma. Br J Dermatol. 2003;149(3):572-7.

3. Freitag FM, Cestari TF, Leopoldo LR, Paludo P, Boza JC. Effect of melasma on quality of life in a sample of women living in southern Brazil. J Eur Acad Dermatol Venereol. 2008;22(6):655-62.

4. Taborda MLVV, Weber MB, Freitas ES. Avaliação da prevalência de sofrimento psíquico em pacientes com dermatoses do espectro dos transtornos psicocutâneos. An. Bras. Dermatol. 2005;80(4):351-4.

5. Cantino A, Zambaldi CF, Sougey EB, Rennó JJ. Transtornos psiquiátricos no pós-parto. Rev. psiquiatr. clín. 2010;37(6):278-84.

6. Secretaria de Estado da Saúde de São Paulo (SES). Coordenadoria de Planejamento em Saúde. Assessoria Técnica em Saúde da Mulher. Atenção a gestante e a puérpera no SUS. Manual técnica do pré natal e puerpério. [Internet] São Paulo, SES; 2010. p. 19 [acesso em 06 set 2013]. Disponivel: http://www.abenfosp.com. br/mt/manual_ses.pdf

7. Bardin L. Análise de conteúdo. Ed. rev. atual. Lisboa: Edições 70; 2009.

8. Schilder PA. Imagem do corpo: as energias construtivas da psique. São Paulo: Martins Fontes; 1999.

9. Griep RH, Aquino EML, Chor D, Kakeshita IS, Gomes ALC, Nunes MAA. Confiabilidade teste-reteste de escalas de silhuetas de autoimagem corporal no Estudo Longitudinal de Saúde do Adulto. Cad. Saúde Pública. 2012;28(9). [acesso em 3 set 2013]. Disponível: http:// dx.doi.org/10.1590/S0102-311X2012000900017

10. Galiás I. Psiquiatria e dermatologia: o estabelecimento de uma comunicação bidirecional. Rev. Junguiana. 2002;(20):57-62.

11. Reche G, Heiderscheidt I, Thives FM, Rosa RA. Camuflagem cosmética: o uso da maquiagem para a correção dos defeitos da pele. [Internet] [acesso em 8 ago 2013]. Disponível: http://siaibib01.univali.br/pdf/ Gabriela\%20Rech\%20e\%20Isete\%20Heiderscheidt.pdf

12. Nogueira LSC, Zancanaro PCQ, Azambuja RD. Vitiligo e emoções. An. Bras. Dermatol. 2009;84(1):39-43.

13. Costa DG, Moreira JA, Pinto MM. Vitiligo: influência na autoestima das pessoas acometidas. Rev. Enferm. Integrada. 2009;2(2):357-68.

14. Tasoula E, Gregoriou S, Chalikias J, Lazarou D, Danopoulou I, Katsambas A, et al. O impacto da acne vulgar na qualidade de vida e saúde psíquica em jovens adolescentes na Grécia: resultados de uma pesquisa populacional. An. Bras. Dermatol. 2012;87(6):862-9.

15. Silva JDT, Muller MC. Uma integração teórica entre psicossomática, stress e doenças crônicas de pele. Estud. Psicol. 2007;24(2):247-56.

16. Dominguez AR, Balkrishnan R, Ellzey AR, Pandya AG. Melasma in latina patients: cross-cultural adaptation and validation of a quality-of-life questionnaire in Spanish language. J Am Acad Dermatol. 2006;55(1):59-66.

17. CestariTF,HexselD, ViegasML,AzulayL,HassunK,Almeida AR, et al. Validation of a melasma quality of life questionnaire for Brazilian Portuguese language: the MELASQoL-BP study and improvement of QoL of melasma patients after triple combination therapy. Br J Dermatol. 2006;156(Suppl 1):13-20. 
18. Purim KS, Avelar MF. Fotoproteção, melasma e qualidade de vida em gestantes. Rev. Bras. Ginecol. Obstet. 2012;34(5):228-34.

19. Balkrishnan R, Kelly AP, McMichael A, Torok H. Improved quality of life with effective treatment of facial melasma: the pigment trial. J. Drugs Dermatol. 2004;3:377-81.

20. Camillo SO, Maiorino FT. A importância da escuta no cuidado de enfermagem. Cogitare enferm. 2012;17(3):549-55.

21. Ludwig MWB, Oliveira MS, Muller MC, Gonçalves AMBF. Localização da lesão e níveis de stress em pacientes dermatológicos. Estud. Psicol. Online (Campinas). [Internet] 2008;25(3) [acesso em 10 ago 2013]. Disponível: http://dx.doi.org/10.1590/S0103166X2008000300003 